\title{
Molybdenite as a Rhenium Carrier: First Results of a Spectroscopic Approach Using Synchrotron Radiation
}

\author{
Teresa Pereira da Silva ${ }^{1 *}$, Maria-Ondina Figueiredo ${ }^{1,2}$, Daniel de Oliveira ${ }^{1}$, \\ João Pedro Veiga ${ }^{2}$, Maria João Batista ${ }^{1}$ \\ ${ }^{1}$ Unit of Mineral Resources and Geophysics, National Laboratory for Energy and Geology, Amadora, Portugal \\ ${ }^{2}$ Faculty of Sciences and Technology, Campus da Caparica, New University of Lisbon, Lisbon, Portugal \\ Email: "teresa.pena@lneg.pt
}

Received June 12, 2013; revised July 16, 2013; accepted July 28, 2013

Copyright (C) 2013 Teresa Pereira da Silva et al. This is an open access article distributed under the Creative Commons Attribution License, which permits unrestricted use, distribution, and reproduction in any medium, provided the original work is properly cited.

\begin{abstract}
The chemical and physical properties of rhenium render it a highly demanded metal for advanced applications in important industrial fields. This very scarce element occurs mainly in ores of porphyry copper-molybdenum deposits associated with the mineral molybdenite, $\mathrm{MoS}_{2}$, but it has also been found in granite pegmatites and quartz veins as well as in volcanic gases. Molybdenite is a typical polytype mineral which crystal structure is based on the stacking of [SMo-S] with molybdenum in prismatic coordination by sulphide anions; however, it is not yet clearly established if rhenium ions replace $\mathrm{Mo}^{4+}$ cations in a disordered way or else, if such replacement gives rise to dispersed nanodomains of a rhenium-rich phase. As a contribution to clarify this question, an X-ray absorption spectroscopy (XANES) study using synchrotron radiation was performed at the Re $L_{3}$-edge of rhenium-containing molybdenite samples. Obtained results are described and discussed supporting the generally accepted structural perspective that rhenium is mainly carried by molybdenite through the isomorphous replacement of Mo, rather than by the formation of dispersed Re-specific nanophase(s).
\end{abstract}

Keywords: Molybdenite Polytypes; Rhenium; Re $L_{3}$ Absorption Edge; XANES

\section{Introduction}

Rhenium (Re) was the last naturally occurring element to be discovered, with a mean concentration in the earth's crust of the order of $1 \mathrm{ppb}$ [1]. This very scarce element has been found in granite pegmatites and quartz veins (e.g. in Japan [2]) as well as in volcanic gases, namely from the Kudryavy Volcano, Kurile Islands [3], but it occurs mainly in ores of porphyry copper-molybdenum deposits [4-9] associated to molybdenite, $\mathrm{MoS}_{2}$, generally recognized as the main Re-carrier in nature $[10,11]$. Indeed, specific rhenium minerals are so far confined to very few sulphides among which rheniite, $\mathrm{ReS}_{2}[12]$ expected to be structurally identical to synthetic rhenium disulphide [13] despite its crystal structure has not yet been fully determined [14], and tarkianite $(\mathrm{Cu}, \mathrm{Fe})(\mathrm{Re}$, Mo $)_{4} \mathrm{~S}_{8}$ [15], a lacunar kenotetrahedral [16] thiospinel.

The unique combination of physical and chemical properties of rhenium and its alloys makes this element extremely attractive, particularly as a coating (being highly refractory and resistant to corrosion), thus highly de-

"Corresponding author. manded in a great diversity of industrial fields, from the production of high-temperature super-alloys for aircraft engines to catalysts in the production of lead-free highoctane gasolines [17]. Rhenium has been extracted mainly as a by-product of the copper mining industry, once the metal is oxidized to the molecular compound dirhenium heptaoxide in the course of roasting molybdenum sulphide ores [18], being subsequently recovered from the flue dusts under the form of ammonium perrhenate [19]. The largest world rhenium producer is currently Chile, followed by the United States, Peru and Poland [20].

The hypothesis that rhenium-content of molybdenite could be enhanced in the rhombohedral polytype was raised by the study of molybdenite polytypism addressed in detail forty years ago [21-24]. Nevertheless, the way rhenium is incorporated is not yet clearly establishedthat is, if Re-ions just replace Mo-ions in a disordered way and in real dependence from the polytype or else, if rhenium forms specific nanophase(s) and occurs concentrated in nanodomains. With the purpose of contributing 
to clarify this long-lasting question, an X-ray absorption spectroscopy study at the Re $L_{3}$-edge was conducted on various molybdenite samples using synchrotron radiation. The results of this spectroscopic approach are described and discussed as an attempt to improve the understanding of Re-minerochemical behaviour in its natural carrier.

\subsection{Rhenium Position in the Periodic Table: Relation with Neighbouring Elements}

With ground state electronic configuration [Xe] $4 f^{14} 5 d^{5}$ $6 s^{2}$, this $5 d$ element is positioned in the $7^{\text {th }}$ column of the Periodic Table, along with manganese (Mn, a $3 d$ element) and technetium (Tc, a $4 d$ element). Intriguingly, rhenium overall behaviour is much closer to molybdenum (Mo), a $4 d$ element belonging to the previous column $\left(6^{\text {th }}\right)$, rather than to tungsten (W), the neighbour $5 d$ element in this column.

Formal valences of rhenium range from -1 to +7 and the stability of this very high oxidation state has rendered this element particularly relevant for the production of catalysts [25]. The most stable ionic state is $4+$ and the ionic radius of $\operatorname{Re}^{4+}(0.72 \AA)$ is close to the radii of $\mathrm{Mo}^{4+}$ and $\mathrm{W}^{4+}$ (both around $0.70 \AA$ ) [26], thus favouring a random substitution by rhenium in the isostructural minerals molybdenite $\left(\mathrm{MoS}_{2}\right)$ - the common molybdenum ore component recognized as the main Re-carrier-and tungstenite $\left(\mathrm{WS}_{2}\right)$, a very rare mineral isostructural with molybdenite but usually carrying much less rhenium.

Rhenium has two naturally occurring isotopes: ${ }^{185} \mathrm{Re}$ (stable, amounting to $37.4 \%$ ) and ${ }^{187} \operatorname{Re}(62.6 \%)$, unstable but with a very long half-life and decaying to the stable ${ }^{187} \mathrm{Os}$, thus allowing for the radiometric dating of molybdenite $[27,28]$.

\subsection{Structural Characteristics of Molybdenite}

The crystal structure of molybdenite - natural molybdenum disulphide, $\mathrm{MoS}_{2}$ - was determined ninety years ago [29]. It is based on the stacking of [S-Mo-S] layers with $\mathrm{Mo}^{4+}$ cations in prismatic coordination between two superimposed closest-packed layers of $\mathrm{S}^{2-}$ anions. The occurrence of such layers gives rise to the already mentioned polytypism, the common natural molybdenite polytype being hexagonal and currently labelled $2 \mathrm{H}(C 7$ structure-type [29]; a natural rhombohedral polytype (labelled 3R) was reported for the first time fifty years ago $[21,22]$. In the seventies, synthetic $\mathrm{MoS}_{2}$ polytypes were the object of a detailed structural analysis [30].

The closest packed anionic layers in $2 \mathrm{H}$ polytype (space group $\mathrm{P}_{3} / m m c$ ) display a sequence [AABB...] according to the usual closest packing notation [31], whereas a sequence [AABBCC...] is observed in the $3 \mathrm{R}$ polytype (trigonal, space group $\mathrm{R} 3 m$ ).

Another interesting structural possibility, so far only theoretical, is the $2 \mathrm{H}_{2}$ polytype [32] similar to the common structure $2 \mathrm{H}$ in what concerns the sequence of [SMo-S] layers, but with a distinct arrangement of molybdenum ions suggesting the possibility of Mo-Mo interactions.

Between successive prismatic planar modules, additional octahedral and tetrahedral interstices are available which are unfilled in molybdenite but which could be locally occupied by ions other than $\mathrm{Mo}^{4+}$, with suitable coordination requirements, giving rise to dispersed nanodomains of another phase.

The possible correlation between the rhenium content of a natural molybdenite and its polytype has been addressed long ago [33] but so far not fully interpreted [9, 34].

\section{Experimental}

The X-ray absorption spectroscopy study of rhenium carried by molybdenite samples with various provenances was undertaken at the Re $L_{3}$-edge and obtained XANES spectra were compared with the $\mathrm{W} L_{3}$-edge XANES spectrum collected from synthetic tungstenite, isostructural with $\mathrm{MoS}_{2}$. The close energy of $\mathrm{Re}$ and $\mathrm{W}$ absorption edges allowed for the performance of one single X-ray absorption experiment at the European Synchrotron Radiation Facility, ESRF.

\subsection{Materials}

The Merlin zone of the Mount Dore copper deposit in NW Queensland, Australia, discovered in 2008 [6], is considered the world's highest grade molybdenum-rhenium sulphide mineralization. A sample from this deposit containing around $10 \mathrm{ppm}$ of Re (reference MDQ0191$58 \mathrm{~m} @ 0.42 \% \mathrm{Mo}, 9.86 \mathrm{~g} / \mathrm{t}$ Re and $0.12 \% \mathrm{Cu}$ from 254 meters [35]) was studied, along with a fragment from a rhenium-rich molybdenite museum specimen from Aldfield, Quebec/Canada [36] where molybdenite occurs in a pyroxene-rock associated with other sulphides, namely pyrite and pyrrhotite [37].

The synthetic compound $\mathrm{WS}_{2}$ is a commercial product from Sigma-Aldrich.

The studied materials were previously characterized by X-ray diffraction (XRD) in the laboratory using a Philips PW 1500 powder diffractometer with Bragg-Brentano geometry equipped with a large-anode copper tube and a graphite crystal monochromator. A detailed scanning $\left(1 / 2^{\circ} / \mathrm{min}\right)$ of suitable angular region $\left(28^{\circ}-52^{\circ} 2 \theta\right)$ was performed to ascertain the polytype of molybdenite samples. To reduce the preferential orientation of comminuted grains, the fragments were hand-milled with glass. Both molybdenite samples displayed the common $2 \mathrm{H}$ polytype structure, as well as synthetic $\mathrm{WS}_{2}$. 


\subsection{Spectroscopic Methodology}

$\mathrm{X}$-ray absorption experiments were carried out at the ESRF (Grenoble, France) using the instrumental set-up of beam line BM-23. XANES spectra were collected using a Si (111) double-crystal monochromator with detuning for harmonic rejection, assuring an energy resolution of about $0.8 \mathrm{eV}$ close to the $L_{3}$ absorption edge of Re metal.

The energy range of the beam line makes it possible to perform in one single experiment the scanning of both rhenium and tungsten $L_{3}$ absorption edges (10.535 and $10.207 \mathrm{keV}$ respectively), thus allowing to compare the XANES spectra of the two cations $\left(\mathrm{Re}^{4+}\right.$ and $\left.\mathrm{W}^{4+}\right)$ and ascertain if they display identical coordination.

Rhenium-rich molybdenite samples were directly irradiated to detect the fluorescence yield using a 13-element Ge-detector. A pressed pellet of the slightly ground model compound mixed with boron nitride was prepared in a proportion adequate to optimize the absorption jump while minimizing the total absorption, in this way improving the display of edge features from the XANES spectrum collected in transmission mode. The energy calibration was assured by irradiating a rhenium metal foil.

\section{Results and Discussion}

Re $L_{3}$-edge XANES spectra obtained from the molybdenite samples (polytype 2H) are reproduced in Figure 1; these spectra display identical layouts $\left(\operatorname{Re} L_{3}\right.$-edge at $10.538 \mathrm{keV}$; first post-edge feature $0.014 \mathrm{keV}$ and sec-

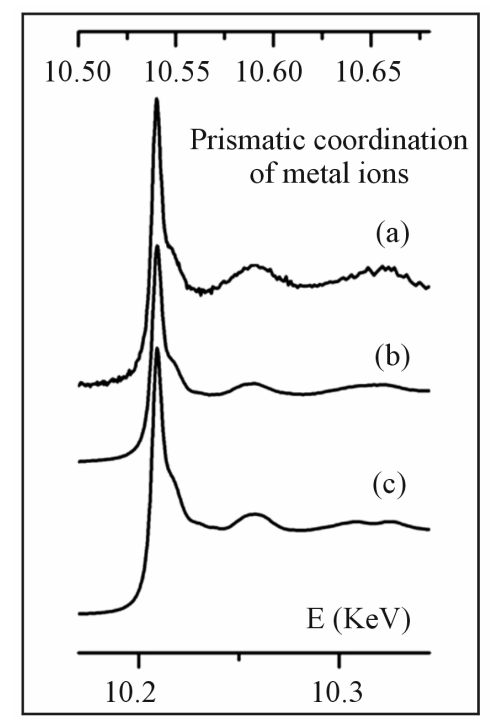

Figure 1. Re $L_{3}$-edge XANES spectra collected from molybdenite samples (energy scale on the top), combined with W $L_{3}$-edge spectrum from the synthetic model compound (energy scale on the bottom). (a) Re-rich $2 \mathrm{H}$-molybdenite from Aldfield, Canada; (b) Re-rich $2 \mathrm{H}$-molybdenite from Merlin, Australia; (c) synthetic tungstenite, $\mathrm{WS}_{2}$. ond $0.052 \mathrm{keV}$ after the edge), quite coincident with the

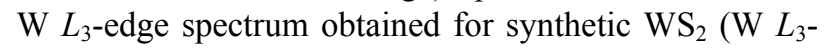
edge at $10.207 \mathrm{keV}$; first post-edge feature $0.014 \mathrm{keV}$ and second $0.050 \mathrm{keV}$ after the edge). The similarity of XANES spectra conforms to the generally accepted idea that $\mathrm{Re}^{4+}$ ions present in molybdenite replace $\mathrm{Mo}^{4+}$ ions in a disordered way, assuming a prismatic coordination like $\mathrm{W}^{4+}$ ions in $\mathrm{WS}_{2}$.

As an attempt to certify such replacement, a theoretical simulation of Re $L_{3}$-edge XANES spectrum in rhenium disulphide - a stable compound with a triclinic crystal structure [13] — was carried out using the FEFF program [38]. The crystallographic data used [13] consider two different rhenium atoms; accordingly, XANES functions were calculated for a cluster size of $10 \AA$, with centers at atom $\operatorname{Re}_{1}$ and atom $\operatorname{Re}_{2}$ as absorbers. The simulated compound spectrum was placed to match the white-line of the experimental $\operatorname{Re} L_{3}$-edge XANES spectrum collected from the Merlin molybdenite sample. The calculated spectrum displays features close to the edge that differ from the details observed in the experimental spectrum (Figure 2), reflecting a distinct electronic behaviour of rhenium in both disulphides.

The differences assigned in the spectral features close to the absorption edge stem from the distinct structural arrangements of $\mathrm{ReS}_{2}$ and $\mathrm{MoS}_{2}$. The crystal structure of rhenium disulphide is a triclinic distortion of $\mathrm{CdCl}_{2}$-type basic structure (C19 crystal structure-type [39]) where $\mathrm{Re}^{4+}$ ions fill two distinct structural sites with approximately octahedral environment by sulphide anions. The structural distortion gives rise to short metal-metal distances configuring Re-Re bonds arranged in $\left[\mathrm{Re}_{4}\right]$ parallelograms [13]. Despite the occurrence of planar modules [S-Re-S] in rhenium disulphide, the atomic arrangement of Re ions within these layers differs significantly from that observed for [S-Mo-S] layers in the $2 \mathrm{H}$ structural array of molybdenite.

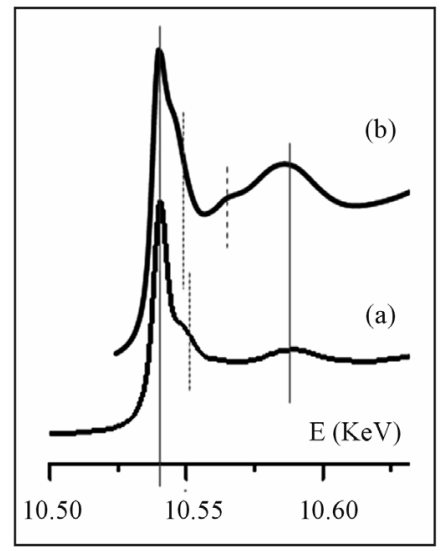

Figure 2. Re $L_{3}$-edge XANES spectrum collected from Merlin molybdenite sample (a), compared with the theoretical spectrum calculated for rhenium disulphide (b). 
The observed differences in Re $L_{3}$-edge XANES spectra reproduced in Figure 2 therefore discard the hypothesis that rhenium occurs in nanodomains of $\mathrm{ReS}_{2}$ within the host molybdenite, in accordance with data from previous authors [28] that used a commercial product as a $\mathrm{ReS}_{2}$ reference material.

\section{Comment and Conclusion}

Data from the experimental spectroscopic approach to rhenium in natural molybdenites and the theoretically calculated $\operatorname{Re} L_{3}$-edge XANES spectrum for synthetic rhenium disulphide converge towards the conclusion that rhenium is carried (hosted) by molybdenite through the replacement of Mo preferably to forming Re-specific nanophase(s). Nevertheless, further work is needed to support the generality of this conclusion by applying scanning electron microscopy and X-ray absorption spectroscopy to a larger diversity of samples in what concerns both molybdenite provenance, rhenium content and polytype ( $2 \mathrm{H}$ or $3 \mathrm{R})$.

\section{Acknowledgements}

Work developed within the project MinReMol (Ref. EXPL/AAG-REC/0978/2012, COMPETE: FCOMP-010124-FEDER-027516) financed by FEDER Funds through "Programa Operacional Factores de Competitividade (COMPETE)" and by National Funds through FCT (Fundação para a Ciência e a Tecnologia). Thanks are due to Mr. Paul Carter of Ivanhoe Australia for the gracious supply of sample MDQ0191. EU financial support to perform the X-ray absorption experiments at the ESRF is acknowledged. Authors affiliated to CENI-MAT/I3N acknowledge the support of the Strategic Project-LA252011-2012 (ref. PEst-C/CTM/LA0025/2011).

\section{REFERENCES}

[1] I. Noddack and W. Noddack, "Die Geochemie des Rheniums," Zeitschrift für Physikalische Chemie, Vol. 154, Abt. A, 1931, pp. 207-244.

[2] S. Ishihara, "Rhenium Contents of Molybdenites in Granitoid-Series Rocks in Japan," Economic Geology, Vol. 83, No. 5, 1988, pp. 1047-1051. doi:10.2113/gsecongeo.83.5.1047

[3] A. A. Kremenetsky and I. V. Chaplygin, "Concentration of Rhenium and Other Rare Metals in Gases of the Kudryavy Volcano (Iturup Island, Kurile Islands)," Doklady Earth Sciences, Vol. 430, No. 1, 2010, pp. 114-119. doi:10.1134/S1028334X10010253

[4] B. Aminzadeh, J. Shahabpour and M. Maghami, "Variation of Rhenium Contents in Molybdenites from the Sar Cheshmeh Porphyry Cu-Mo Deposit in Iran," Resource Geology, Vol. 61, No. 3, 2011, pp. 290-295. doi:10.1111/j.1751-3928.2011.00165.x

[5] A. N. Berzina, V. I. Sotnikov, M. Economou-Eliopoulos and D. G. Eliopoulos, "Distribution of Rhenium in Molybdenite from Porphyry $\mathrm{Cu}-\mathrm{Mo}$ and $\mathrm{Mo}-\mathrm{Cu}$ Deposits of Russia (Siberia) and Mongolia," Ore Geology Reviews, Vol. 26, No. 1-2, 2005, pp. 91-113.

doi:10.1016/j.oregeorev.2004.12.002

[6] M. Brown, F. Lazo, P. Carter, B. Goss and D. Kirwin, "The Geology and Discovery of the Merlin Mo-Re Zone of the Mount Dore Deposit, Mount Isa Inler, NW Queensland, Australia," SGA News, Vol. 27, No. 1, 2010, pp. 915.

[7] A. I. Grabezhev and E. S. Shagalov, "Rhenium Distribution in Molybdenite: Results of Microprobe Scanning (Copper Porphyry Deposits, the Urals)," Doklady Earth Sciences, Vol. 431, No. 1, 2010, pp. 351-355. doi:10.1134/S1028334X10030189

[8] O. B. Lavrov and L. V. Kuleshevich, "The First Find of Rhenium Minerals in Karelia," Doklady Earth Sciences, Vol. 432, No. 1, 2010, pp. 598-601. doi:10.1134/S1028334X10050107

[9] P. C. Voudouris, V. Melfos, P. G. Spry, L. Bindi, T. Kartal, K. Arikas, R. Moritz and M. Ortelli, "Rhenium-Rich Molybdenite and Rheniite in the Pagoni Rachi Mo-Cu$\mathrm{Te}-\mathrm{Ag}-\mathrm{Au}$ Prospect, Northern Greece: Implications for the Re Geochemistry of Porphyry-Style Cu-Mo and Mo Mineralization," Canadian Mineralogist, Vol. 47, No. 5, 2009, pp. 1013-1036. doi:10.3749/canmin.47.5.1013

[10] M. Fleischer, "The Geochemistry of Rhenium, with Special Reference to Its Occurrence in Molybdenite," Economic Geology, Vol. 54, No. 8, 1959, pp. 1406-1413. doi:10.2113/gsecongeo.54.8.1406

[11] K. Terada, S. Osaki, S. Ishihara and T. Kiba, "Distribution of Rhenium in Molybdenites from Japan," Geochemical Journal, Vol. 4, No. 3, 1971, pp. 123-141. doi:10.2343/geochemj.4.123

[12] M. A. Korzhinsky, S. I. Tkachenko, K. I. Shmulovich, Y. A. Taran and G. S. Steinberg, "Discovery of a Pure Rhenium Mineral at Kudriavy Volcano," Nature, Vol. 369, No. 6475,1994 , pp. 51-52. doi: $10.1038 / 369051 \mathrm{a} 0$

[13] H. H. Murray, S. P. Kelty and R. R. Chianelli, "Structure of Rhenium Disulfide," Inorganic Chemistry, Vol. 33, No. 19, 1994, pp. 4418-4420. doi:10.1021/ic00097a037

[14] V. S. Znamensky, M. A. Korzhinsky, G. S. Steinberg, S. I. Tkachenko, A. I. Yakushev, I. P. Laputina, I. A. Bryzgalov, N. D. Samotoin, L. O. Magazina, O. V. Kuzmina, N. I. Organova, V. A. Rassulov and I. V. Chaplygin, "Rheniite, $\mathrm{ReS}_{2}$, the Natural Rhenium Disulphide from Fumaroles of of Kudryavy Volcano, Iturup Island, Kurile Islands," Proceedings of the Russian Mineralogical Society, Vol. 134, No. 5, 2005, pp. 32-39.

[15] K. K. Kojonen, A. C. Roberts, O. P. Isomäki, V. V. Knauf, B. Johanson and L. Pakkanen, "Tarkianite, $(\mathrm{Cu}, \mathrm{Fe})(\mathrm{Re}, \mathrm{Mo})_{4} \mathrm{~S}_{8}$, a New Mineral Species from the Hitura Mine, Nivala, Finland," Canadian Mineralogist, Vol. 42, No. 2, 2004, pp. 539-544. doi:10.2113/gscanmin.42.2.539

[16] G. Kullerud, G. Donnay and J. D. H. Donnay, "Omission Solid-Solution in Magnetite: Kenotetrahedral Magnetite," Zeitschrift für Kristallographie-Crystalline Materials, Vol. 128, No. 1-2, 1969, pp. 1-17. 
[17] A. Naor, N. Eliaz, E. Gileadi and S. R. Taylor, "Properties and Applications of Rhenium and Its Alloys," AMMTIAC Quarterly, Vol. 5, No. 1, 2010, pp. 11-15.

[18] B. Krebs, H. Müller and H. Beywr, "A New Type of Oxide Structure: The Crystal Structure of Rhenium (VII) Oxide," Chemical Communications (London), Vol. 1968, No. 5, 1968, pp. 263-264.

[19] KGHM Ecoren, 2007. http://en.ecoren.pl/rhenium.xml

[20] K. Salazar and M. K. McNutt, "Mineral Commodity Summaries 2012," US Geological Survey, Reston, Virginia, 2012.

[21] R. J. Traill, "A Rhombohedral Polytype of Molybdenite," Canadian Mineralogist, Vol. 7, No. 3, 1963, pp. 524-526.

[22] Y. Takeuchi and W. Nowacki, "Detailed Crystal Structure of Rhombohedral $\mathrm{MoS}_{2}$ and Systematic Deduction of Possible Polytypes of Molybdenite," Schweizer Mineralogische und Petrographische Mitteilungen, Vol. 44, No. 1, 1964, pp. 105-120.

[23] F. E. Wickman and D. K. Smith, "Molybdenite Polytypes in Theory and Occurrence. I. Theoretical Considerations of Polytypism in Molybdenite," American Mineralogist, Vol. 55, No. 11-12, 1970, pp. 1843-1856.

[24] J. W. Frondel and F. E. Wickman, "Molybdenite Polytypes in Theory and Occurrence. II. Some Naturally-Occurring Polytypes of Molybdenite," American Mineralogist, Vol. 55, No. 11-12, 1970, pp. 1857-1875.

[25] S. R. Bare, S. D. Kelly, F. D. Vila, E. Boldingh, E. Karapetrova, J. Kas, G. E. Mickelson, F. S. Modica, N. Yang and J. J. Rehr, "Experimental (XAS, STEM, TPR, and XPS) and Theoretical (DFT) Characterization of Supported Rhenium Catalysts," Journal of Physical Chemistry C, Vol. 115, No. 13, 2011, pp. 5740-5755. doi:10.1021/jp1105218

[26] L. H. Ahrens, "The Use of Ionization Potentials Part 1. Ionic Radii of the Elements," Geochimica et Cosmochimica Acta, Vol. 2, No. 3, 1952, pp. 155-169. doi:10.1016/0016-7037(52)90004-5

[27] D. Selby and R. A. Creaser, "Macroscale NTIMS and Microscale LA-MC-ICP-MS Re-Os Isotopic Analysis of Molybdenite: Testing Spatial Restrictions for Reliable Re-Os Age Determinations, and Implications for the Decoupling of Re and Os within Molybdenite," Geochimica et Cosmochimica Acta, Vol. 68, No. 19, 2004, pp. 38973908. doi:10.1016/j.gca.2004.03.022
[28] Y. Takahashi, T. Uruga, K. Suzuki, H. Tanida, Y. Tereda and K. H. Hattori, "An Atomic Level Study of Rhenium and Radiogenic Osmium in Molybdenite," Geochimica et Cosmochimica Acta, Vol. 71, No. 21, 2007, pp. 51805190. doi:10.1016/j.gca.2007.08.007

[29] Strukturbericht Band 1, 1913-1926, pp. 164-166.

[30] A. N. Zelikman, G. V. Indenbaum, M. V. Teslitskaya and V. P. Shalankova, "Structural Transformations in Synthetic $\mathrm{MoS}_{2}$," Soviet Physics Crystallography, Vol. 14, No. 1, 1970, pp. 687-691.

[31] J. Lima-de-Faria and M. O. Figueiredo, "Standard Sheets for Condensed Models of Crystal Structures. I. Structures Based on Close Packings," Garcia de Orta, Sér. Geologia, Vol. 13, No. 1, 1990, pp. 43-58.

[32] R. J. J. Newberry, "Polytypism in Molybdenite (I): A NonEquilibrium Impurity-Induced Phenomenon," American Mineralogist, Vol. 64, No. 7-8, 1979, pp. 758-767.

[33] M. Ya. Somina, "Trigonal Molybdenite from East Siberian Carbonatite," Procd. Earth Sci. Sect, Vol. 167, 1966, pp. 898-901.

[34] V. Melfos, M. Vavelidis, A. Filippidis, G. Christofides and E. Evangelou, "Re-Rich and Re-Poor Molybdenite in the Maronia Rhyolitic Intrusion, Northeastern Greece," In: M. Pagel and J. L. Leroy, Eds., Source, Transport and Deposition of Metals, Balkema, 1991, pp. 775-777.

[35] "High-Grade Molybdenum and Rhenium Intercepts Drilled on Ivanhoe Australia's Merlin Project," 2009. http://www.ivanhoe-mines.com/i/pdf/2009-03-24_IAL_N R.pdf

[36] A. Machado e Costa, "Inventory of Minerals," Mineralogical and Geological Museum of Lisbon University, Lisbon, 1937.

[37] T. L. Walker, "Report on the Molybdenum Ores of Canada," Government Printing Bureau, Department of Mines, Ottawa, No. 93, 1911, pp. 30-31.

http://www.archive.org/details/reportonmolybden00walkr ich

[38] A. L. Ankudinov, B. Ravel and J. J. Rehr, "Manual of FEFF8.10 Program," The FEFF Project, Department of Physics, University of Washington, Seattle, 2000.

[39] Strukturbericht Band 1, 1913-1926, pp. 742-743. 